\title{
DIE NAVORSINGSTAAK VAN DIE UNIVERSITEIT
}

\section{Inleidende opmerkinge}

Die navorsingsdrang by die mens spruit voort uit sy skepping na die beeld van God. Daarkragtens bespeur hy in die heelal die polupoikilos sophia, die veelkleurige wysheid (van God).

Die mens wat ' $n$ weinig minder as 'n goddelike wese gemaak is (Ps. $8: 6$ ) aanskou o.m. die hemel, die werk van Gods vingers, en hy weet dat die Skepper hom laat heers oor die werke van sy hande. Ons eeu kan daarvan getuig. Watter fantastiese navorsingsresultate is nie reeds bereik nie en nog steeds speur die gees van die mens verder!

Die Bybelgelowige weet egter ook dat daar 'n stadium kom waarin gesê word: Trek jou skoene van jou voete af want die plek waar jy staan is heilige land. "Wat is die mens dat $U$ aan hom dink en die mensekind dat U hom besoek?" (Ps. $8: 5$ ).

Hy weet ook dat daar in die goeie skepping van God 'n wanklank gekom het vanweë die mag van die duisternis, sodat gespreek kan word van 'n sugtende skepping en skepsel. Die Bybel praat van die Leviatan, Rahab, die ou slang, ens. Die navorser sal ook met die feit rekening moet hou. Hy het eenvoudig nie met ' $n$ "normale" heelal te doen nie.

Daar word gewoonlik onderskei tussen ,fundamentele" (of „basiese”) en „toegepaste" navorsing. Fundamentele (of basiese) navorsing het ten doel die vermeerdering en verdieping van kennis. Toegepaste navorsing bied uitsluitlik hulp in die oplossing van praktiese probleme. Sowel by fundamentele as by toegepaste navorsing word ' $n$ hoë peil vereis en trivialiteite uitgesluit. Dit sou dus ontoelaatbaar wees om 'n Ph.D.-verhandeling wat handel oor ,skottelgoedwas" as navorsing te bestempel. So 'n verhandeling is werklik geskryf - en wel met die oog op die bemarkbaarheid van die boek. ${ }^{1}$

\section{Navorsing gedurende die eeue}

Die Middeleeuse universiteite het hulle hoofsaaklik toegelê op die verspreiding van kultuur deur middel van die dosering van teologie, filosofie en die ,artes”. Wetenskaplike navorsing was prakties onbekend. ${ }^{2}$ 
Voorop het gestaan die gedagte dat die doel van alle onderrig moet wees: hulp aan studente om hulle eie lewes waardiglik te lewe, met volle begrip van hulself en hul plek in die gemeenskap.

Gedurende die Middeleeue bly die universiteite grotendeels instellinge waarin die enigste wetenskap die Aristoteliese dogma moes wees.

Frankryk was die eerste land wat die beoefening van georganiseerde wetenskaplike navorsing in praktyk gebring het. Die Akademie van Parys wat in 1671 'n toelae van Lodewyk XIV ontvang het, sou deur die hele agtiende eeu uitnemende werk doen, sodat Parys die onbetwiste hoofstad van die wetenskap in Europa word. ${ }^{3}$

Tog is in dieselfde agtiende eeu die universitêre onderwys in Europa beskou as die mededeling van 'n vasstaande geheel van kennis wat deur die student as waarheid opgeneem moes word, om eventueel gereproduseer te word.

Hierdie gedagte het in die Middeleeue ontstaan en die universiteite bly beheers. Dit was verwant aan die stelsel van die stilswygend aangehoorde katedervoordrag, die dikteermetode, waarby die student noukeurig opteken. „De student verrichte ieder college-uur opnieuw het wonder van het gelijktijdig luisteren, begrijpen en opschrijven en aan het einde stond hij op in de gelukzalige stemming waarvoor Goethe de klassiekgeworde uitdrukking heeft gegeven: Was man schwarz auf weiss besitzt kann man getrost nach Hause tragen'".4

Aan die begin van die $18 \mathrm{e}$ eeu was die Duitse universiteite nog in die greep van die Middeleeuse Skolastiek. Van die begin van die $19 \mathrm{e}$ eeu begin sake egter verander en kom daar selfstandige denke, sodat die filosofie nie meer die ancilla theologiae is nie maar 'n selfstandige wetenskap. Die Duitse universiteite volg nou die Franse patroon en lê hulle toe op navorsing en die opleiding van navorsers.

Die prestige van die Duitse universiteite het gestyg tot onbekende hoogtes en is deur Engeland en Amerika beny. Die Duitsers het die wêreld gelei op navorsingsgebied en studente van oor die hele aarde getrek.

Brittanje beskou teen die middel van die negentiende eeu Duitsland as 'n model. In 1868 skryf die Oxfordse humanis Mark Pattison die volgende merkwaardige woorde: „What I wish to contend is that the professor of a modern university 
ought to regard himself primarily as a learner and a teacher only secondarily ... No teacher who is a teacher only, and not himself a daily student..., can be competent to treat any of the higher parts of any moral or speculative science".

Tog het die nuwe burgerlike universiteite, soos Oxford en Cambridge, die wetenskap maar weer gaan doseer met die oog op die toepassing daarvan. Die tegnologie word beliggaam binne die universiteite.

In ander universitêre kringe het egter die vrees ontstaan dat navorsing (en veral toegepaste navorsing) die onderwyselement in die universiteite sal laat verdwyn. Terselfdertyd het sommige van hulle die bestaande stelsel van promosie van universiteitspersoneel op grond van navorsingswerk onderskrywe!s

Die situasie is tans so dat Amerika Europa ver agtergelaat het wat navorsing betref. Hierdie swakheid sal ongetwyfeld uitgebuit word deur Rusland met sy geweldige navorsingspotensiaal. Navorsing bepaal die leierskap in die toekoms en die Soviet-Unie is besig om Europa in hierdie opsig verby te strewe.

Gelukkig word die noodsaaklikheid van 'n wetenskapsbeleid wat die gebalanseerde ontwikkeling van fundamentele navorsing sal verseker allerweë gevoel. Dit is immers ' $n$ nasionale belegging op lang termyn, omdat fundamentele navorsing 'n skeppende mag agter alle wetenskaplike ontwikkeling is. ${ }^{6}$

\section{Die plek en betekenis van navorsing in die universiteits- wese}

Verreweg die meeste navorsing wat van die $18 \mathrm{e}$ eeu tot vandag verrig is, het aan die universiteite plaasgevind. En tog verklaar prof. H. L. de Waal nog in 1961, dat daar veels te min navorsing aan ons Suid-Afrikaanse universiteite gedoen word, veral omdat dosente dit slegs deeltyds kan verrig en omdat periodieke eksaminering sowel as skaarste aan navorserdosente ook faktore is waarmee rekening gehou moet word. ${ }^{7}$

Prof. G. Cronje, huidige voorsitter van die S.A. Akademie, het in 1963 die volgende stellinge met betrekking tot navorsing aan die universiteite neergelê:

1. In die praktyk kom die toedrag van sake veelal daarop neer dat onderrig die funksie is wat uitgeoefen moet word, ter- 
wyl navorsing die taak is wat afgeskeep kan en selfs mag word.

2. Daar is veels te veel dosente wat nie sinnigheid of bevoegdheid vir navorsing het nie.

3. Mede weens geldgebrek word akademiese personeel meestal in die eerste plek benoem met die oog op die onderwysbehoeftes en nie soseer, en soms glad nie, met die oog op navorsingsbehoeftes nie.

Nie alleen sal die dosente navorsingsbewus moet wees nie maar ook die studente. Hulle moet onthou dat die universiteit nie ' $n$ Kindergarten is waar hulle met geestelike kennislepels gevoer word nie, maar sover moontlik selfstandig dieper in die wetenskap moet indring. ${ }^{8}$

\section{Is navorsing die primêre doel van die universiteit?}

Dit word deur prof. J. Chr. Coetzee ontken. Eerste doel is vir hom die wetenskaplike onderrig met die oog op die opleiding van toekomstige leiers in die verskillende geleerde professies. As hoogste doel sien prof. Coetzee die ideaal van algemene opvoeding, van oordrag van nasionale kultuur. Hy pleit dan ook vir 'n professioneel-opvoedkundige opleiding van die hoogleraar aan die universitêre inrigting. Die professor moet egter ook op navorsingsgebied presteer. Tot sover prof. Coetzee.

Hoewel die referent saamstem dat die universiteit ook opvoedingswerk doen en vir beroepe voorberei, wil hy die saak tog liewer so sien dat die drie take ineenvloei. Die professor wat 'n student en navorser bly en sy studente inspireer tot harde werk, doen tegelyk ook opvoedkundige werk en berei voor vir ' $\mathrm{n}$ beroep, vir sover dit moontlik is (vgl. onder).

Ons is derhalwe meer geneig om saam te stem met $\mathrm{dr}$. S. Meiring Naudé, president van die W.N.N.R. Op 'n konferensie van S.A. Universiteite in 1960 het hy verklaar: „It is generally agreed today that, when a professor is appointed to the staff of a university, the first qualification required is distinction in research work. It is further expected that he will continue with his research work and university councils go out of their way to provide every opportunity to make this possible for him, for it is believed that in his search for new knowledge the professor constantly improves his own mind and inspires his students". 10 
Met ander woorde: die taak van die universiteit is sowel die vermeerdering as die mededeling van kennis. En in werklikheid is daar geen antagonisme tussen die funksie van onderwys en navorsing nie. 'n Universiteitsprofessor moet doseer, navorsingswerkers oplei en self navorser wees. Sover moontlik moet nagraadse studente ook meedoen aan hierdie hoogs noodsaaklike werk. ${ }^{11}$

'n Krisismoment van die huidige universiteit is die feit dat die eise van professionele vorming dermate toeneem dat die akademiese vorming van die student skade ly. Die universiteite word al meer tegniese institute vir beroepsopleiding - wetenskaplike „fabrieke” wat „deskundige materiaal” aan die samelewing moet lewer. Ons ly aan 'n hipertrofie van professionalisme. Hierdie tendens aan die universiteite is vir die beroepe selfs nadelig. Opleiding vir 'n spesifieke beroep beteken nog nie opleiding vir die lewe nie. Studente moet later ook buite hul vak leiding gee en skiet hierin soms te kort vanweë eensydige vorming.12 Stoker stel die vraag: Is dit nie van belang vir die behartiging van ' $n$ latere beroep dat - saam met die professionele opleiding - veral ook aandag gegee word aan 'n meer algemene akademiese vorming van die student nie? Anders loop die universiteit gevaar om te ontaard in 'n halfslagtige vakskool waarby spesialisme dreig om hom tot 'n navorsingsinstituut om te vorm en waarby die hoër onderwys slegs ten dienste van beroepstegniese nuttigheid gestel word. ${ }^{13}$

\section{Navorsing en opvoeding}

Tereg is daarop gewys dat die universiteit nie alleen moet sorg vir 'n hoë peil van akademiese navorsing nie maar ook die onderrig moet moderniseer. Die twee is onlosmaaklik aan mekaar verbonde. As byvoorbeeld die aandag beperk word tot die wetenskaplike taak van die universiteit, bestaan die gevaar dat die onderwys verwurg word deur die wetenskaplike navorsingswerk. ${ }^{14}$

Werklike wetenskaplike navorsing hou egter geen gevaar vir die onderwysaspek in nie. Dit is wel die geval as professore toegepaste navorsing uitoefen vir eie gewin. Tydens sy studietyd aan die universiteite van Chicago en Berlyn het dr. Meiring Naudé opgemerk dat die studente professore verag wat hulle hieraan skuldig maak. Aan die ander kant is profes- 
sore bewonder en vereer wat fundamentele navorsing doen en nuwe terreine open. ${ }^{15}$

In dieselfde rigting dink dr. Posthumus (regeringskommissaris vir die wetenskaplike onderwys in Nederland): „Universitair onderzoek en universitair onderwijs zijn schering en inslag van het zelfde weefsel. Hun draden kunnen worden onderscheiden; zij kunnen niet worden gescheiden zonder vernietiging van de structuur". 16

Navorsing het 'n geweldige invloed op die wyse waarvolgens die opvoedkundige sy taak moet verrig. Dit blyk naamlik dat die herinnering aan die lesings van navorsers die student gedurende sy hele lewe bybly.

Al kan die student nie direk alles inneem nie, word hy tog geprikkel tot intensiewe arbeid, wat van veel meer beteke$n$ is is as wanneer stereotiepe lesings uit die hoof geleer word.

Die beste navorser is self besig met die lewende wetenskap terwyl ander net tradisionele stof kan oorlewer. ${ }^{17}$ Die onderwystaak sal anders en beter verrig word as iemand maar net een of ander tyd 'n substansiële stuk navorsingswerk gedoen het. Onderwys moet verbind word met lewendige navorsing, met oorspronklike werk. Dit is selfs vir die voorgraadse student stimulerend om 'n enkele keer 'n kykie te kry in die gees van die navorser en in die debat tussen wetenskaplikes.

Die eksamenstelsel kan die gedagte wek dat kennis in 'n statiese toestand verkeer, terwyl die doel juis is om die kennis uit die lewende stroom op te diep. So word die student geïnspireer om self soeker van nuwe kennis te word.

Dit is wel so dat slegs 'n klein minderheid van studente die doel het om wetenskaplikes in die volle sin van die woord te wees. Maar adekwate universitêre skoling beklemtoon die skepping en mededeling van nuwe kennis en beskou die reeds versamelde wetenskaplike kennis as 'n agtergrond vir diepergaande navorsing.

Daarom moet navorsers hulle ook besig hou met aktiewe doseerwerk. Die kontak met die wyer velde van 'n onderwerp kan hulle bewaar van altyd dieper in dieselfde groef te delf, wat geestelike aarverkalking kan veroorsaak. ${ }^{18}$

Daarom moet veel meer gebruik gemaak word van doseermetodes wat deelname van die student meebring. „There is nothing more stultifying than the process of passive note-taking by students. There should be fewer lectures, more seminars . " 19 


\section{Navorsing en beroepsopleiding}

In hierdie verband het $d r$. S. Biesheuvel 'n aantal trekke in ons universiteitswese opgemerk wat kommer veroorsaak. Die eerste is dat ons universiteite in 'n groot mate professionele skole geword het en opgehou het om kweekplekke van hoër kennis-te-wees.

Die tweede is dat die navorsingsfunksies van universiteite in toenemende mate deur die staat, staatsondersteunde instellinge en groot industriële laboratoria oorgeneem word. Universiteite kan nie navorsers kweek as die duursame navorsingsprojekte nie vir hulle toeganklik is nie.

'n Derde sorgbarende trek is die feit dat die universiteite veral geantwoord het op die materialistiese waardebepalings van die staat en die individu, tot skade van kennis ter wille van die kennis.

Een van die gevolge is dat oor die algemeen weinig ambisie by studente te sien is om universiteitsdosente te word. Die doseerpligte is gewoonlik swaar en daar is weinig kans om op eie gebied te spesialiseer. ${ }^{20}$

As daar besnoei moet word, moet dit liefs in die spesifiek beroepsmatige opleiding geskied. Die werklike leertyd begin immers eers in die gewone lewe. ${ }^{21}$

Verskillende skrywers beklemtoon die feit dat iemand wat 'n breë opleiding gehad het meer kans op sukses in sy eie beroep het as iemand wat net vir een sekere beroep opgelei is. Sommige beskou selfs die toekenning van grade nie as ' $n$ fundamentele taak van die universiteit nie. ${ }^{22}$

Ook hier spreek Jaspers 'n ware woord as hy sê: „Forschung im Sinne des Findens neuer allgemein-gültiger Erkenntnis ist etwas Grosses, aber ihre Haltung ist von der des Finders des rechten Tuns durch keine scharfe Grenze getrennt". ${ }^{23}$

Vanweë oorbeklemtoning van die professionele vereistes in die akademiese opleiding het twee hoofpligte van die universitêre taak op die agtergrond geraak:

1. Die gee van algemene vorming aan alle studente sonder onderskeid van studierigting of akademiese graad.

2. Die besteding van die groots moontlike aandag aan die opkweking van 'n potensieel hoogs begaafde jonger generasie wat ensiklopedies gevorm word om te fungeer as 'n intel- 
lektuele avant-garde, die sg. „creative minority” van Toynbee.

Hierdie tweeledige versuim begin hom dubbel en dwars te wreek..$^{24}$

Vir beroepsopleiding is die beste vorming nie die instamp van afgeslote (sic!) kennis nie maar die oefening en ontplooiing van die organe van wetenskaplike denke - en hoe kan dit beter geskied as deur die aankweek van 'n navorsershouding? Dit is veel beter as om vir dwase eksamens 'n hoeveelheid kennis in te pomp wat spoedig weer vergeet word. Die vernaamste is om die probleme raak te sien en die metodes te beheers. „Ausbildung zum Forscher und Ausbildung zur Befähigung in praktischen ist dasselbe".

Dit is nie die doel van universitêre studie om studente met hulle laaste eksamen as perfekte wetenskaplike vakkragte ter beskikking van die beroep te stel nie. Dit is nie die taak van die universiteit om aan die kerk die afgerigte predikant, aan die skool die gevormde onderwyser en aan die industrie die wetenskaplik afgeronde ingenieur te voorsien nie.

Die universiteit kan net die Selbstausbildung en die ontwikkeling van die metodies-wetenskaplike denke waarborg, waardeur hulle goeie dokters, ingenieurs ens. kan word en ook met die ontwikkeling van die tyd en die wetenskap nuwe take raaksien.2s

\section{Suggesties in verband met die toekoms}

As daar ooit 'n tyd was waarin navorsing deur die universiteit op intensiewe wyse angepak moet word, dan is dit ongetwyfeld ons tyd.

Dr. Fred. L. Polak beskryf die situasie soos volg:27

„Vandaag is een spoedige, serieuse bezinning op deze hoofd- en halszaak waarlijk geboden, wegens het alle barrières doorbrekend tijdsverloop met zijn ,Umwertung aller Werte'. De bedoelde na-oorlogse periode mag zonder overdrijving worden gekenschetst als een van in turbulent tempo voortschrijdende industrieel-technische, internationaal-politieke en sociaal-culturele revolutie". „Misschien zullen de geschiedschrijvers van de toekomst gewagen van een nieuwe, in onze tijd plaatsgrijpende Copernicaanse wending".

Polak sien veral twee hoofprobleme wat uitmond in die 
oeroue maar vir ons tyd so totaal nuwe lewens- en wesensvraag: wie en wat is die mens - hoe bestaan hy en waarheen gaan hy?

Die eerste probleem is: hoe kan die mens in 'n deur homself vrywillig aan die tirannie van die tegniek prysgegewe, steeds meer versaaklikte, geuniformeerde wêreld, hom nog op pluriforme wyse as persoon, dus as geestelik volwaardige mens handhaaf en ontplooi?

Die tweede probleem is: hoe kan die mens, skepper en slaaf van 'n demoniese verwoestingstegniek, nietemin 'n vreedsame samelewing met die medemens op aarde ontplooi?

Hoewel die mens reeds in 'n groot mate oor die natuur heers, blyk dit dat hy homself die minste van almal kan beheers.

In so 'n wêreld kan universitêre navorsing 'n geweldige taak verrig, veral as dit „in U lig” geskied. In hierdie lig word immers die oplossing vir alle vraagstukke gebied, ook van die grootste vraagstuk - die mens self.

\section{Die uitvoering van die toekomstaak in die Republiek van Suid-Afrika}

As die gestelde navorsingstaak na behore vervul moet word sal daar na ons vaste oortuiging 'n totaal nuwe universiteitspatroon moet kom.

Waar die huidige vandaan kom is moeilik te sê. Vermoedelik is dit egter kragtens historiese ontwikkeling in 'n ruime mate 'n Britse patroon, wat radikaal van die Europese-kontinentale en selfs van die Amerikaanse verskil. In alle beskeidenheid word 'n paar riglyne vir die toekoms aangebied. In hoever hulle prakties toegepas kan word, is ' $n$ ander vraag. Maar waar ' $n$ wil is, is 'n weg en met die oog op die erns van die tye moet hierdie weg gesoek word.

1. Daar sal intensief gewerk moet word deur dosent sowel as student. Vir elke vooruitgang in kennis is harde, onvermoeide werk nodig. Werk is die basis van alles. Dit vra dissipline en orde.

Dit sal alreeds 'n groot oorwinning wees as die naweekgees oorwin kan word wat daartoe aanleiding gee dat van Vrydag $1 \mathrm{~nm}$. nie meer gewerk word nie, dus - vier en 'n halwe dag uit die sewe is arbeidsdae!

As ons die Christelike Westerse beskawing in ons land wil behou sal dit ' $n$ radikaal ander houding teenoor die wetenskap 
vra en ook teenoor spel en sport. Dit gaan om ons voortbestaan, al dan nie, en die Weste kan hier leer by die Russe wat alles veil het vir hulle ideologie. Sal ons in Suid-Afrika die leierskap behou, moet daar hard en steeds harder nagevors word en sal ontspanning slegs diensbaar moet wees aan groter prestasie. Ons vra nie wat ander universiteite doen nie, maar hoe ons die wetenskaplike peil op die doeltreffendste wyse kan bevorder.

Daar het al stemme opgegaan dat die akademiese jaar verleng moet word. Die referent is egter oortuig dat dit lank genoeg is as dit maar reg gebruik word. Gans te veel tyd word bestee aan 'n oormaat van sosiale bedrywighede en 'n oormaat van sport.

Niemand misgun die student die lewensblyheid, sport en vermaak nie, maar dit is ten slotte bysaak. Ons land en volk ja, die koninkryk van God vra die beste van elke burger.

2. Met die oog op die feit dat die oorgang van middelbare skool na universiteit blykbaar te groot is en die neiging waargeneem word om die vereistes aan die universiteit dienooreenkomstig enigsins te verswak, kan die instelling van 'n propedeutiese jaar oorweeg word, sodat die voorbereiding vir die B-graad vier jaar duur, soos in Amerika. In die laaste twee jaar kan moontlik reeds deelgeneem word aan navorsingsprojekte.

3. Gedurende die eerste vier jaar doen die studente „kollege"werk, terwyl die werklike universitêre werk begin met die magisters- en doktorsgrade - grootliks toegespits op navorsing.

4. Die beste studente en dosente moet gestimuleer word om aan gevorderde navorsing mee te doen. Wat dosente betref sou dit seker aanbevelenswaardig wees om diegene wat hulle besonderlik in navorsingswerk interesseer, soveel moontlik van kollegewerk te verskoon, sonder om die kontak met studente heeltemal te verloor.

5. As ons egter aanvaar dat meer navorsing en opleiding van groter getalle navorsers (ook die werk van die universiteit) nodig is, moet die geriewe en geleenthede daarvoor voorsien word. ${ }^{28}$

'n Onlangse verslag aan die Minister van Onderwys, Kuns en Wetenskap in Nederland het bepleit:

(1) 'n drievoudige vermeerdering van die dosente binne enkele jare in die fakulteit Wis- en Natuurkunde en (2) die bou van laboratoria vir universitêre navorsing met 'n tempo wat 
ongeveer tienmaal sneller as die bestaande moet wees. ${ }^{29}$

Universiteite behoort nie suinig te wees in verband met navorsing nie, maar dit beskou as een van die vernaamste obligasies om navorsings- en publikasietoelaes toe te ken aan verdienstelike werkers. As daar besnoei moet word, moet navorsing- en publikasietoelaes die laaste wees om onder die valbyl te kom. ${ }^{30}$

In hierdie verband moet met besondere klem die betekenis van die W.N.N.R. en die R.G.N. vermeld word. Albei hierdie rade skakel ten nouste met die universiteite en ontvang van die staat aansienlike bedrae vir navorsing, waarvan ook universiteitsdosente en -studente kan profiteer. Op die Rade dien tans dan ook verskillende persone wat op een of ander wyse met universiteite in verband staan.

Vir ons Universiteit is daar 'n heerlike taak om te volvoer. Sir Walter Moberley vertel dat die filosofiese fakulteit van 'n groot Amerikaanse Universiteit na nuwe geboue oorgetrek en voorgestel het dat bo aan die hoofingang die woorde van Protagoras ingegraveer sou word: Die mens is die maatstaf van alles. Die rektor het egter anders gedink en toe die Universiteit weer heropen na 'n vakansie het bo die ingang die volgende woorde uit Psalm 8 gestaan: Wat is die mens dat $U$ aan hom dink $?^{31}$

Hiermee word aan 'n Christelike Universiteit 'n fundamentele taak gestel. In hierdie woorde word saamgevat die saak waarom dit finaliter gaan. Mag ons Universiteit waarlik navorsing doen in $U$ lig, waardeur tegelyk opgevoede mense en mense wat bekwaam is vir die lewenstaak gevorm word, terwyl die dosente die Christelike wetenskap verryk.

Mag ons altyd hierdie woorde van die gevierde Vlaamse voordragkunstenaar, prof. Lauwerys, onthou: Die stryd tussen Oos en Wes sal nie op die slagveld nie, mar in die studeerkamers en die klaskamers beslis word.

\section{P.U. vir C.H.O.}

S. du Toit

1 Vgl. S. R. Dongerkery: Universities and their problems, Bombay, 1948 , p. 44.

2 Ibid., p. 2.

3 S. M. Naude, in: Conference of South African Universities, 11th and 
12th April, 1960, p. 3.

4 E. J. Dijksterhuis: Historische wording en actuele situatie van die Universiteit, in: Kernvragen van de Universiteit, Den Haag, '1954, p. 16.

5 S. M. Naude: a.w., p. 4-9.

6 Bem David: Fundamental Research and the universities, Paris, 1968 , pp. 7, 8

7 In: Navorsing in S.A. - waarheen? Pretoria, 1961, pp. 2, 3.

$8 \mathrm{Vgl}$. Jaarboek van die S.A. Akademie, 1963, en referate gelewer op Alg. Vergadering van die Akademie, 1967, pp. 23, 24.

$9 \mathrm{Vgl}$. Beginsels en Metodes van die Hoër Onderwys (red. J. Chr Coetzee en D. J. van Rooy), Pretoria, 1949, pp. 23, 25.

10 A.a., p. 3

11 Vgl. Dongerkery: a.w., p. 91.

12 Stoker, in: Beginsels en metodes in die wetenskap, Pro Rege, Potchefstroom, 1961, pp. 17-18.

13 P. G. W. du Plessis, in: Gevraagde Universiteit, Publikasiereeks Univ van Port Elizabeth, nr. 3, 1967, pp. 3, 4

14 H. J. Wolther: Aangehaal deur Naude: a.w., p. 8.

15 A.w., p. 9.

16 De universiteit - doelstellingen, functies, structuren, Den Haag, 1968 , p. 11

17 Aldus Karl Jaspers in: Jaspers-Rossmann: Die Idee der Universitdt, Berlin, ens., 1961, pp. 68, 73-77.

$18 \mathrm{Vgl}$. H. Butterfield: The Universities and education today, Londen, 1961, p. 21.

$19 \mathrm{Vgl}$. S. Biesheuvel: The changing function of the universities, University of Natal Press, 1965, p. 12.

20 A.w., p. iv.

21 Polak in: Het hoger onderwijs, op de helling of op een hellend vlak? Leiden, 1961, p. 17.

22 Vgl. G. L. Brook: The modern university, Londen, 1965, p. 16.

23 A.w., p. 70

24 Polak: a.w., pp. 14, 15

25 Jaspers: a.w., p. 70.

26 Rossmann in: Jaspers-Rossmann: a.w., p. 199.

27 A.w., p. 4.

28 In: Navorsing in Suid-Afrika - waarheen? (Simposium van die Akademie, 1961), p. 4.

29 Aangehaal deur De Waal: a.w., p. $2-4$

30 Dongerkery: a.w., p. 97.

31 The crisis in the University, Londen, 1949, p. 55. 